accompanied by W. H. Julius and W. H. Wilterdinck, of Leiden, and will probably make Padang his headquarters. Somewhere in the neighbourhood of Padang, also, the American astronomers, Prof. Barnard and Prof. Todd, together with a party from the Washington Observatory, and another party from the Lick Observatory, are expected to set up their instruments. Prof. Campbell has selected Mr. C. D. Perrine to take charge of the expedition from the Lick Observatory, and this observer will be accompanied by Mr. R. E. Curtiss, of the Observatory at Berkeley; the expenses of the expedition will be defrayed by the well-known liberal benefactor to science, Mr. W. H. Crocker, of San Francisco. The Observatory has further learned, through Father Cortie, that certain members of the Calcutta Jesuit Mission will also go to Padang to observe the eclipse.

The most direct route to Padang from Europe is by the Rotterdam-Lloyd line of steamers ; a steamer leaving Southampton on April 9 and Marseilles on April 18 is due at Padang on May 12, and there is a return steamer on May 24, due at Marseilles on June I8. Return tickets at greatly reduced rates may be obtained through the British Astronomical Association.

As to the work to be undertaken, the great duration of totality emphatically demands that almost every effort should be directed towards the corona. Indeed, the study of the chromosphere and prominences during eclipses may well be considered to have reached a halting-place, so that in any case the study of these appendages would be considered of secondary importance. The great success which has attended the observation of recent eclipses has in some degree placed observation ahead of solar theory, and it is perhaps for this reason that most of the observations which, we understand, are to be undertaken are along familiar lines. To a certain extent this is, of course, inevitable, for it is always rightly regarded as a prime duty to record the phenomena as completely as possible.

Adequate provision is made for securing pictorial records of the corona. Some of these will be on a large scale to show the finer details of the lower reaches, and others on a smaller scale to depict the extensions seen with the naked eye. Messrs. Maunder and Claxton will utilise the photoheliograph of the Mauritius Observatory, giving pictures of the sun nearly 8 inches in diameter, and in addition will be provided with a 4 -inch coronagraph fitted with a negative enlarging lens to give images 2 inches in diameter; the long extensions will be specially attacked with a 4 -inch Dallmeyer R.R. lens of 32 inches focus.

At Padang, Mr. Dyson will erect the Thompson photoheliograph of 9 inches aperture, which was successfully employed by the Astronomer Royal in India and Portugal, the photographs being enlarged by a magnifier to a scale of 4 inches to the sun's diameter. The same observer will also take charge of a double camera with 4 -inch lenses of relatively short focus to grasp the feeble rays of the longer streamers.

It is probable that Prof. Barnard's instrument will be the coronagraph of $6 \mathrm{I}$ feet focus, with which he obtained such admirable photographs of the prominences and inner corona last May. Prof. Todd will again employ his wholesale method of obtaining photographs with cameras in which the exposures are given and plates changed automatically. Coronagraphs of 33 feet 3 inches and 5 -feet focus will form part of the equipment of the Jesuit Mission.

For the spectroscopic records, Mr. Maunder is provided with the 2 -inch prismatic camera with which $\mathrm{Mr}$. Evershed secured valuable photographs during the eclipse of 1898 . With this type of instrument, the principles of which are now sufficiently familiar to render a description superfluous, the spectra of both corona and chromosphere are recorded in the most complete manner. A modified prismatic camera, in the form of an objective grating, will be employed by Mr. Newall in an attempt to photograph the coronal rings. Mr. Dyson will again employ the two slit spectroscopes belonging to Captain Hills, which were used in India and Portugal, one of them being specially adapted for the ultra-violet spectrum. Another important spectroscope will be the prismatic camera forming part of Dr. Nÿland's equipment ; this consists of a 6-inch objective and two prisms of $45^{\circ}$, thus duplicating one of the instruments employed in the last two eclipses by Sir Norman Lockyer. The Jesuit Mission will investigate the spectroscopic phenomena with a Rowland concave grating of 36 inches focus, and a prismatic camera of 33 inches focus.

In the case of the slit spectroscopes and the objective grating, the long duration of totality will obviously be an immense advantage, and it is very desirable also that the experiment of giving very long exposures with the prismatic cameras should be made.

Among the more special inquiries, Mr. Newall will again attempt to investigate the rotation of the corona, and also to obtain photographs of the corona in polarised light. The first of these observations is a particularly delicate one, depending for its success on photographically recording the coronal spectrum with sufficient dispersion to exhibit the minute displacements of the bright lines produced by the rotation. The long duration of totality is especially favourable for this observation, but, on the other hand, there is evidence that at the time of sun-spot minimum the coronal lines are of but feeble intensity. Success is therefore by no means assured, but the slit spectroscope to be employed in the experiment is one of great efficiency and convenience, and the attempt is well worth making.

The study of the polarisation of the coronal light is also of some importance. The luminosity of the corona, apart from that due to the luminous gases of the inner corona, has been ascribed to the reflection of solar light by the small particles of which it is supposed to consist, and to the direct emission of light by such particles rendered incandescent by solar radiation. The bolometric observations of Prof. Langley's party at the last eclipse, however, led to the conclusion that the corona appears "neither to reflect much light from the sun, nor, chiefly by virtue of a high temperature, to give light of its own, but seems rather to be giving light in a manner not associated with high temperature" (NATURE, vol. Ixiii. p. 67). On the other hand, Mr. Newall, during the same eclipse, found a marked polarisation of the coronal light, indicating that a considerable proportion of the light is reflected. The accumulation of additional data bearing on the origin of the light of the corona, therefore, seems very desirable.

The fact that a British man-of-war will be sent to Padang to render assistance to Messrs. Dyson and Newall is a sufficient guarantee that an adequate record of the general phenomena of the eclipse will be made.

A. FOWLER.

\section{RED RAIN.}

$A \mathrm{~N}$ unusual, though it can scarcely be called a rare, meteorological phenomenon is reported from Italy, and has been made the subject of much highly coloured descriptive writing in the daily Press. The plain facts are thus given by Reuter's correspondent in Palermo in a telegram dated March Io:

"Since last night a dense lurid cloud has hung over this town. The sky appears of a sinister blood red hue, and a strong south wind is blowing. The drops of rain

$$
\text { No. } 1637 \text {, voL. 63] }
$$


that fall are like blood. The phenommon, which is known by the name of blood rain, is attributed to dust from the Sahara Desert, carried here by the wind." And the Rome correspondent of the Auency on the same date says: "The phenomena reported from Sicily have also been observed in Southern Italy. The sky here has a yellow tint, and a violent sirocco is sweeping over the city. At Naples showers of sand have fallen, and the phenomenon of the Fata Morgana has been observed, the sky being of a deep red colour."

Later reports from Algiers describe the same occurrence in North Africa, and the explanation suggested is no doubt correct. It is simply a case of fine sand raised to a great height by one of the "dust devils" or whirlwinds of the Sahara, and carried by the movement of the upper air to a considerable distance before the particles, resisted in their fall by the friction of the air, have succeeded in reaching the ground. If rain happens to fall through such a cloud of suspended dust it naturally carries down a good deal of the material with it, and leaves red stains on drying up. If there is no rain, the fall of dry dust takes place all the same, and this effect is well known at sea in the trade-wind belt west of the Sahara.

It must be remembered that another kind of "blood rain," even more effective in appealing to the fears of the ignorant and superstitious, owes its alarming tint to the presence of minute organisms similar to those of red snow.

Dust rains of one kind or another are fairly frequent. Those of "sulphur" have been traced to the pollen blown abroad from conifers in the spring, and those of "ink," unhappily commoner in this country, to the catching up of smoke from manufacturing districts. Such a black rain, accompanied by intense darkness, fell over nearly 500 square miles in the north of Ireland in February 1898 during a spell of north-easterly wind, while in May 18c9 a similar phenomenon was reported over an equal area of central and south-western England.

The precise atmospheric conditions necessary for the raising of dust or smoke into the upper parts of the atmosphere, and for the concentration and descent over special areas, is not yet fully understood; but the careful meteorological observations now made in many parts of Italy may be expected to throw some light on the general phenomenon when dealing with the recent occurrence.

\section{DR. G. M. DAWŚNON, C.M.G., F.R.S.}

GEOLOGICAL science, and Canada in particular, have suffered an irreparable loss in the death of George Mercer Dawson, C.M.G., LL.D., F.R.S., the director of the Geological Survey of that Dominion. He was born at Pictou, Nova Scotia, on August I, I 849 , and was the eldest surviving son of the late Sir John William Dawson, whose death was recorded in NATURE for November 23, 1899.

After studying at the McGill Lniversity in Montreal, he came to London and entered the Royal School of Mines in 1869. Here he gained the Duke of Cornwall's scholarship and the Edward Forbes and Murchison medals, thus passing with distinction as an Associate of the School. The training which he received in biology, as well as in geology and mining, was of essential service in his after career.

Having returned to Canada, he was in 1873 appointed geologist and botanist to the North American Boundary Commission, and two years later he joined the staff of the Geological Survey of Canada, becoming assistant director in 1883 and director in 1895 .

No. 1637 , vOL. 63 ]
For nearly thirty years he was thus actively engaged in field-work, gaining a broad and firm grasp of the leading features in the geology of Canada. If, as he himself remarked, much of his work was "of an exploratory character, and only occasionally, and then to a limited extent, precise or finished," it has been none the less important in advancing the science of geology and in furthering the development of the mineral resources of the Dominion. Far better equipped as a pioneer than was possible in the early days of geology, and keen in the examination of fresh ground, his enthusiasm was tempered only by the reluctance in leaving unsolved those problems which required further detailed study. In spite of constitutional infirmity, he possessed a marvellous amount of energy, while as a companion and leader he gained the confidence and affection of all who had the privilege of working with him.

$\mathrm{H}$ is contributions to science, though mainly geological, were imbued with a general knowledge of natural history, and included observations on such subjects as seals, locusts and freshwater sponges. In geology he dealt at times with all the great formations, with volcanic rocks, with changes in the level of land, and with fluctuations of the great $A$ merican lakes. In one of his earlier papers, communicated to the (ieological Society of London, he described the glacial phenomena of the central regions of North America, and attributed the deposits of the great plain to the action of floating ice. In later papers he gave accounts of the remarkable evidences of glaciation in British Columbia, and of the shore-lines and terraces which extend from the present sea-level up to a height of more than 5000 feet. He then maintained the marine origin of the drifts of the western plains, but stated his opinion without dogmatism, or, as he puts it (in the British Association Handbook of Canada), "under all reserve and subject to further inquiry."

Many of his geological observations were embodied in his official reports, commencing with a general description of the Tertiary Lignite formation which overlaps the Cretaceous strata of the Red River - a report prepared for the British North American Boundary Commission. On the Geological Survey his work lay principally in British Columbia and the North-IVest Territory. The economic resources necessarily occupied much attention, and the mines and minerals, as well as the more purely scientific problems, were investigated as fully as possible in Vancouver Island, Queen Charlotte's Island, the Yukon territory, and in all parts of British Columbia. He contributed also to journals and transactions of societies in the United States as well as in Canada.

In later years his time was so largely occupied with administrative work, and in the preparation of his annual reports of the progress of the Geological Survey in Canada, that he had little time for recreation. The full value of his work has hardly as yet been appreciated, but there is no doubt that his name will stand in the forefront among Canadian geologists. It is already written permanently in Dawson city, of gold-bearing fame, in recognition of his able researches in that region.

In 1891 he was elected a Fellow of the Royal Society of London, and in the same year he was appointed one of H.M. Behring Sea Commissioners. During the inquiry connected with this Commission he made personal observations on the natural history of seals, and his services were officially recognised by his being made C.M G. In 1891 also he was awarded the Bigsby Medal by the Council of the Geological Society of London, in appreciation of the value of his researches into the geological structure of Canada. In 1893 he was elected president of the Royal Society of Canada, and in 1896 he was chosen president of Section $\mathrm{C}$ at the Toronto meeting of the British Association.

He died on March 2 after a brief illness. 